\title{
Coxiella burnetii Seroprevalence and Risk Factors in Cattle Farmers and Farm Residents in Three Northeastern Provinces and Inner Mongolia Autonomous Region, China
}

\author{
Wu-Wen Sun, Wei Cong, Mao-Hui Li, Chun-Feng Wang, \\ Xiao-Feng Shan, and Ai-Dong Qian \\ College of Animal Science and Technology, Jilin Agriculture University, Changchun, Jilin Province 130118, China \\ Correspondence should be addressed to Ai-Dong Qian; qianaidong0115@163.com
}

Received 21 September 2015; Revised 29 December 2015; Accepted 10 January 2016

Academic Editor: Daniele Corsaro

Copyright ( $\odot 2016 \mathrm{Wu}$-Wen Sun et al. This is an open access article distributed under the Creative Commons Attribution License, which permits unrestricted use, distribution, and reproduction in any medium, provided the original work is properly cited.

\begin{abstract}
Little is known about Coxiella burnetii infection among cattle farmers and farm residents in China. Thus, the present study was conducted to detect the seroprevalence of $C$. burnetii infection and estimate associated risk factors among cattle farmers and farm residents in China. A cross-sectional study was designed, and sera of 362 people living or working on 106 cattle farms were tested for C. burnetii IgG and IgM antibodies by immunofluorescence assay. Overall C. burnetii seroprevalence was 35.6\% (129/362, 95\% CI: 30.70-40.57), and 112 participants had experienced a past infection and seventeen (4.7\%) had experienced a relatively recent infection. In the final combined multilevel model, the following activities were significantly associated with presence of antibodies against $C$. burnetii: milking cattle, providing general healthcare to cattle, providing birth assistance, contact dead-born animals, urbanization, and presence of mice and/or rats in the stable. Moreover, presence of disinfection equipment was a significant protective factor. This is the first study addressing the seroprevalence and risk factors of C. burnetii infection in cattle farmers and farm residents in three northeastern provinces and Inner Mongolia Autonomous Region, China.
\end{abstract}

\section{Introduction}

Q fever, caused by Coxiella burnetii (C. burnetii), is a ubiquitous zoonotic disease. Cattle, sheep, and goats are considered as the primary animal reservoirs for human infection. C. burnetii are shed in particularly high concentrations in placentas and birth fluids of infected animals, which may subsequently contaminate the stable environment [1]. Human get infections with C. burnetii mostly by inhalation of contaminated aerosols coming from parturient animals and their birth products [2-4]. Clinical symptoms of acute Q fever usually present as a self-limited febrile illness, hepatitis, or pneumonia, with very little proportion evolving into chronic infections [5-7].

Q fever has outbroken in people in some countries, including Spain [8], Switzerland [9], Great Britain [10], Germany [11], and Netherlands [12]. Infections are usual occupational risk in persons working with livestock and contacting with highly infectious aerosols from birth products, milk, urine, faeces, or semen of infected animals [13]. These occupational risk populations include workers in slaughterhouses, meat-packing plants, and tanneries as well as veterinarians and farmers [13]. In China, infection has been detected in humans as well as in a wide range of wild, domestic, and farmed animals such as cattle, goats, dogs, pigs, mice, sheep, and horses [14]. In the previous study, we reported the seroprevalence of $C$. burnetii infection in farmed ruminants including cattle in the three northeastern provinces and Inner Mongolia Autonomous Region, China [15]. However, information on the seroprevalence and risk factors for acquisition of $C$. burnetii infection in cattle farmers and farm residents is limited. Thus, the aim of the present study was to determine the seroprevalence in farmers and household members living and/or working on cattle farms and to assess the farmrelated and individual risk factors for seropositivity in order to update control measures and to provide targeted advice for this occupational group and the China cattle industry. 


\section{Materials and Method}

2.1. Study Population and Data Collection. This study was approved by the Animal Ethics Committee of Jilin Agriculture University, China. All cattle farms in three northeastern provinces and Inner Mongolia Autonomous Region with at least 50 cattle that were not vaccinated for Q-fever were selected from the register in the census of the zone. As an important cattle and sheep breeding base in China, with the development of economy, farms with different sizes were settled up quickly in Inner Mongolia Autonomous Region. The three northeastern provinces (Jilin, Liaoning, and Heilongjiang provinces) are comprehensive agricultural bases. Poultry, pigs, cattle, sheep, and deer are the main breeding animals in these areas. On eligible farms, we approached cattle farmers and one or two of their household members aged 12 years and older, and in some cases, other persons working or living on the farm such as farm employees. A maximum of five participants were included per farm. Nonresponders received a reminder 3 weeks after the initial invitation. After providing informed consent on farm and individual level, all participating farms were visited by professional laboratory assistants, who collected sera from October 2013 through July 2014. Each participant completed a questionnaire about personal characteristics (e.g., age, medical history, farm-related activities, contact with livestock and companion animals, and use of personal protective equipment). The farm owner or manager completed a questionnaire about herd size, cattle housing, presence of other livestock and companion animals, farm facilities, and hygiene measures.

2.2. Serological Method. An immunofluorescence assay (IFA) (Focus Diagnostics, Cypress, CA, USA) was used to test serum samples for C. burnetii phases I and II IgM and IgG. All samples were screened at an initial dilution of $1: 32$; those with negative results were considered negative. Positive samples were further classified as indicative of relatively recent infections (IgM phase II titer $>32$ ) or past infections (IgG phase II titer $>32$ and IgM phase II titer $<32$ ). Samples with all other outcomes were considered negative. The term relatively recent was chosen because phase II IgM is commonly found up to 1 year after infection in acute $Q$ fever cases, but it may persist up to 3 years [16]. Phases I and II IgG end point titers were determined for all seropositive persons. In agreement with chronic $Q$ fever diagnostic criteria used in the Netherlands [17], phase I IgG titers $\geq 1,024$ in samples in the past infection group were considered indicative of possible chronic infection.

2.3. Statistical Analysis. Results were analyzed with SPSS 19.0 software package. For comparison of the frequencies among the groups, the Mantel-Haenszel test and when indicated the Fisher exact test were used. Bivariate, multivariate, and multilevel analyses were used to assess the association between participant- and farm-based characteristics of the subjects and the C. burnetii infection. Variables were included in the multivariate analysis if they had a $P$ value of equal or less than 0.20 in the bivariate analysis. Adjusted odd ratio (OR) and 95\% confidence interval were calculated
TABLE 1: Participant characteristics and Coxiella burnetii seroprevalence among cattle farmers and farm residents in three northeastern provinces and Inner Mongolia Autonomous Region, China.

\begin{tabular}{lcccc}
\hline Variable & Category & $\begin{array}{c}\text { Freq. } \\
(N)\end{array}$ & $\begin{array}{c}\text { Seroprevalence } \\
(\%)\end{array}$ & $95 \%$ CI \\
\hline Participant & & 362 & 35.64 & $30.70-40.57$ \\
\hline \multirow{2}{*}{ Sex } & Male & 198 & 36.36 & $29.66-43.06$ \\
& Female & 164 & 34.76 & $27.47-42.04$ \\
\hline \multirow{4}{*}{ Age group } & $<35$ & 56 & 35.71 & $23.16-48.26$ \\
& $35-44$ & 78 & 30.77 & $20.53-41.01$ \\
& $45-54$ & 137 & 38.69 & $30.53-46.84$ \\
\multirow{5}{*}{ Function } & $\geq 55$ & 91 & 35.17 & $25.35-44.98$ \\
& Farmer & 193 & 38.34 & $31.48-45.20$ \\
& Spouse & 89 & 31.46 & $21.81-41.11$ \\
& Child & 45 & 31.11 & $17.59-44.64$ \\
\multirow{4}{*}{ Region } & Other* & 35 & 37.14 & $21.14-53.15$ \\
\hline & Heilongjiang & 98 & 30.61 & $21.49-39.74$ \\
& Jilin & 76 & 27.63 & $17.58-37.69$ \\
& Liaoning & 92 & 31.52 & $22.03-41.02$ \\
& Inner Mongolia & 96 & 51.04 & $41.04-61.04$ \\
\hline
\end{tabular}

* represents other family members and employees.

by multivariate analysis using multiple, unconditional, and logistic regression. A $P$ value less than 0.05 was considered statistically significant.

\section{Results}

3.1. Descriptive Characteristics. Of all 197 invited eligible cattle farms, 106 (53.8\%) farms participated in this study. The number of cattle farms from Heilongjiang, Jilin, Liaoning, and Inner Mongolia was 21, 28, 22, and 35, respectively. The mean herd size was 95 cattle (range 50-327) in participating farms. From the 106 participating farms, 362 persons provided a blood sample (mean age 46.0 years (12-68), 45.3\% male) (Table 1). All of the farm-based and participant-based questionnaires were completed by the 106 farmers and 362 persons.

3.2. Seroprevalence of C. burnetii. Overall C. burnetii seroprevalence was 35.6\% (129/362, 95\% CI: 30.70-40.57), and seroprevalence among farmers, spouses, children, and others was $38.3 \%, 31.5 \%, 31.1 \%$, and $37.1 \%$, respectively (Table 1 ). Of the 129 seropositive participants, 112 participants had experienced a past infection and seventeen $(4.7 \%)$ had experienced a relatively recent infection, as demonstrated by presence of IgM phase II antibodies. IgG phase II end titers were known for the 76 participants with a past infection with IgG phase I <1:32: 1:32 $(n=25), 1: 64(n=14), 1: 128(n=13)$, $1: 256(n=13), 1: 512(n=10)$, and $\geq 1: 1024(n=1)$. For the 36 participants with a past infection with IgG phase I $\geq 1: 32,3$ persons had "possible chronic Q fever" with IgG phase I titers $\geq 1: 1024$ according to diagnostic standard used in the Netherlands [8]. We could not confirm that these truly were chronic $\mathrm{Q}$ fever cases due to lack of clinical information 
TABLE 2: Bivariate logistic regression analysis of participant-based characteristics associated with Coxiella burnetii positivity among cattle farmers and farm residents in three northeastern provinces and Inner Mongolia Autonomous Region, China.

\begin{tabular}{|c|c|c|c|c|c|}
\hline Variable & Category & $\begin{array}{l}\text { Freq. } \\
(N)\end{array}$ & $\begin{array}{c}\text { Seroprevalence } \\
(\%)\end{array}$ & OR (95\% CI) & $P$ value \\
\hline \multirow{3}{*}{ Work and/or live on farm } & Work and live & 245 & 40.41 & $2.03(0.98-4.22)$ & \multirow{3}{*}{0.023} \\
\hline & Work, but not live & 73 & 26.03 & $1.06(0.45-2.49)$ & \\
\hline & Not working, but live & 44 & 25.00 & Reference & \\
\hline \multirow{4}{*}{ Hours working on farm } & Fulltime & 174 & 37.36 & $1.32(0.65-2.66)$ & \multirow{4}{*}{0.853} \\
\hline & Halftime & 109 & 35.78 & $1.23(0.59-2.59)$ & \\
\hline & Quarter week & 34 & 32.35 & $1.06(0.41-2.76)$ & \\
\hline & Sometimes/never & 45 & 31.11 & Reference & \\
\hline \multirow{4}{*}{ How often in stable } & Every day & 189 & 38.62 & $1.39(0.70-2.79)$ & \multirow{4}{*}{0.426} \\
\hline & Every week & 104 & 35.58 & $1.22(0.58-2.58)$ & \\
\hline & Every month & 38 & 28.95 & $0.90(0.35-2.32)$ & \\
\hline & Less than once a month/never & 31 & 25.81 & Reference & \\
\hline \multirow{2}{*}{ Feeding cattle } & Yes & 299 & 38.45 & $2.19(1.16-4.14)$ & \multirow{2}{*}{0.014} \\
\hline & No & 63 & 22.22 & Reference & \\
\hline \multirow{2}{*}{ Milking cattle } & Yes & 203 & 43.84 & $2.32(1.48-3.65)$ & \multirow{2}{*}{$<0.001$} \\
\hline & No & 159 & 25.16 & Reference & \\
\hline \multirow{2}{*}{ General healthcare of cattle } & Yes & 241 & 42.32 & $2.56(1.55-4.21)$ & \multirow{2}{*}{$<0.001$} \\
\hline & No & 121 & 22.31 & Reference & \\
\hline \multirow{2}{*}{ Remove manure } & Yes & 286 & 35.66 & $1.01(0.59-1.71)$ & \multirow{2}{*}{0.982} \\
\hline & No & 76 & 35.53 & Reference & \\
\hline \multirow{2}{*}{ Spread manure } & Yes & 258 & 40.31 & $2.13(1.28-3.57)$ & \multirow{2}{*}{0.002} \\
\hline & No & 104 & 24.04 & Reference & \\
\hline \multirow{2}{*}{ Clean stables } & Yes & 269 & 39.03 & $1.84(1.09-3.11)$ & \multirow{2}{*}{0.022} \\
\hline & No & 93 & 25.81 & Reference & \\
\hline \multirow{2}{*}{ Birth assistance } & Yes & 216 & 42.59 & $2.19(1.38-3.46)$ & \multirow{2}{*}{$<0.001$} \\
\hline & No & 146 & 25.34 & Reference & \\
\hline \multirow{2}{*}{ Administration } & Yes & 219 & 38.81 & $1.43(0.91-2.23)$ & \multirow{2}{*}{0.076} \\
\hline & No & 143 & 30.77 & Reference & \\
\hline \multirow{2}{*}{ Wear overalls or boots } & Yes & 233 & 38.63 & $1.45(0.92-2.30)$ & 0.110 \\
\hline & No & 129 & 30.23 & Reference & 0.110 \\
\hline Having a dog & Yes & 294 & 35.03 & $0.87(0.51-1.50)$ & 0.619 \\
\hline Having a dog & No & 68 & 38.24 & Reference & 0.619 \\
\hline Having a cat & Yes & 278 & 35.25 & $0.93(0.56-1.55)$ & 0.782 \\
\hline Having a cal & No & 84 & 36.90 & Reference & 0.182 \\
\hline Direct contact with cattle in their own or other farms & Yes & 287 & 38.68 & $2.00(1.12-3.57)$ & 0.018 \\
\hline & No & 75 & 24.00 & Reference & \\
\hline Direct contact with horses in their own or other farms & Yes & 210 & 39.52 & $2.56(1.61-4.07)$ & $<0.001$ \\
\hline Direct contace with horses int thent owir or otmer rarms & No & 152 & 23.68 & Reference & $<0.001$ \\
\hline Contact with raw milk & Yes & 243 & 43.21 & $3.01(1.80-5.04)$ & $<0.001$ \\
\hline Contact witn raw mik & No & 119 & 20.17 & Reference & $<0.001$ \\
\hline Contact with cattle manure & Yes & 225 & 44.00 & $2.80(1.73-4.54)$ & $<0.001$ \\
\hline Contace will caltie manure & No & 137 & 21.90 & Reference & $<0.001$ \\
\hline Contact with dead-born animals & Yes & 196 & 45.41 & $2.62(1.67-4.12)$ & $<0.001$ \\
\hline 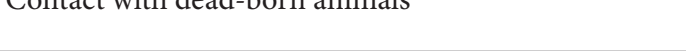 & No & 166 & 24.10 & Reference & $<0.001$ \\
\hline Contact with placenta/birth material & Yes & 188 & 38.30 & $1.27(0.83-1.96)$ & 0.272 \\
\hline Contact with placenta/birth material & No & 174 & 32.76 & Reference & $0.2 / 2$ \\
\hline
\end{tabular}


TABLE 3: Bivariate logistic regression analysis of farm-based characteristics associated with Coxiella burnetii positivity among cattle farmers and farm residents in three northeastern provinces and Inner Mongolia Autonomous Region, China.

\begin{tabular}{|c|c|c|c|c|c|}
\hline Variable & Category & Number of humans tested & Positive (\%) & OR (95\% CI) & $P$ value \\
\hline \multirow{4}{*}{ Region } & Heilongjiang & 98 & 30.61 & Reference & \\
\hline & Jilin & 76 & 27.63 & $0.87(0.45-1.68)$ & 0.667 \\
\hline & Liaoning & 92 & 31.52 & $1.04(0.56-1.93)$ & 0.892 \\
\hline & Inner Mongolia & 96 & 51.04 & $2.36(1.31-4.25)$ & 0.004 \\
\hline \multirow{2}{*}{ Urbanization } & Moderate or minor urban area & 149 & 20.81 & Reference & $<0.001$ \\
\hline & Rural area & 213 & 46.01 & $3.24(2.01-5.24)$ & \\
\hline \multirow{3}{*}{ Herd size } & Small (50-100) & 197 & 32.48 & Reference & 0.393 \\
\hline & Medium (100-150) & 104 & 39.42 & $1.35(0.83-2.22)$ & \\
\hline & Large $(>150)$ & 61 & 39.34 & $1.35(0.74-2.44)$ & \\
\hline \multirow{2}{*}{ Beef cattle on the farm } & Yes & 202 & 37.13 & $1.16(0.75-1.79)$ & 0.505 \\
\hline & No & 160 & 33.75 & Reference & \\
\hline \multirow{2}{*}{ Number of stables } & $>3$ stables & 117 & 32.48 & $0.81(0.51-1.30)$ & 0.386 \\
\hline & $\leq 3$ stables & 245 & 37.14 & Reference & \\
\hline \multirow{2}{*}{ Use of artificial insemination } & Yes & 84 & 46.43 & $1.81(1.10-2.98)$ & 0.018 \\
\hline & No & 278 & 32.37 & Reference & \\
\hline \multirow{2}{*}{ Laying hens on farm } & Yes & 243 & 40.33 & $1.92(1.18-3.11)$ & 0.008 \\
\hline & No & 119 & 26.05 & Reference & \\
\hline \multirow{2}{*}{ Presence of cat(s) in cattle stable } & Present & 198 & 36.36 & $1.07(0.70-1.65)$ & 0.751 \\
\hline & Absent & 164 & 34.76 & Reference & \\
\hline \multirow{2}{*}{ Use of silage } & Yes & 276 & 40.22 & $2.54(1.43-4.51)$ & 0.001 \\
\hline & No & 86 & 20.93 & Reference & \\
\hline \multirow{2}{*}{ Use of maize } & Yes & 288 & 38.19 & $1.79(1.01-3.17)$ & 0.045 \\
\hline & No & 74 & 25.68 & Reference & \\
\hline \multirow{2}{*}{ Feeding method } & Fodder mixer or automatic & 241 & 32.37 & $0.66(0.42-1.03)$ & 0.067 \\
\hline & Hand/wheelbarrow & 121 & 42.15 & Reference & \\
\hline \multirow{2}{*}{ Presence of mice and/or rats in the stable } & Present & 199 & 45.23 & $2.63(1.67-4.14)$ & $<0.001$ \\
\hline & Absent & 163 & 23.93 & Reference & \\
\hline \multirow{2}{*}{ Farm visitors } & Yes & 143 & 37.76 & $1.17(0.75-1.81)$ & 0.495 \\
\hline & No & 219 & 34.25 & Reference & \\
\hline \multirow{2}{*}{ Farm boots for staff } & Yes & 277 & 36.46 & $1.17(0.70-1.95)$ & 0.553 \\
\hline & No & 85 & 32.94 & Reference & \\
\hline \multirow{2}{*}{ Presence of hygienic locker room } & Yes & 269 & 31.97 & $0.55(0.34-0.88)$ & 0.013 \\
\hline & No & 93 & 46.24 & Reference & \\
\hline \multirow{2}{*}{ Presence of disinfection equipment } & Yes & 224 & 29.46 & $0.50(0.32-0.77)$ & 0.002 \\
\hline & No & 138 & 45.65 & Reference & \\
\hline \multirow{2}{*}{ Birds in stable } & Yes & 90 & 45.56 & $1.75(1.08-2.85)$ & 0.023 \\
\hline & No & 272 & 32.35 & Reference & \\
\hline \multirow{2}{*}{ Veterinary service } & Yes & 301 & 31.62 & $1.40(0.78-2.54)$ & 0.273 \\
\hline & No & 61 & 29.51 & Reference & \\
\hline \multirow{2}{*}{ Type of farm management } & Closed herd & 298 & 34.89 & $0.84(0.48-1.46)$ & 0.528 \\
\hline & Purchase of cattle & 64 & 39.06 & Reference & \\
\hline
\end{tabular}

(e.g., presence of vascular infection, endocardial involvement, or other clinical risk factors).

3.3. Risk Factors for C. burnetii Infection. All individual and farm-based variables, which were tested in the bivariate analysis for relationship with human C. burnetii seropositivity, are shown in Tables 2 and 3.
In the multivariate analyses, from 14 individual variables which were associated in the bivariate analysis, six were independently associated with $C$. burnetii seropositivity (Table 4). Moreover, 5/18 farm-based variables included in the multilevel analyses were significantly independent risk or protective factors and together were used as the full multilevel start model (Table 5). 
TABLE 4: Multivariate logistic regression analysis of participant-based characteristics associated with Coxiella burnetii positivity among cattle farmers and farm residents in three northeastern provinces and Inner Mongolia Autonomous Region, China.

\begin{tabular}{|c|c|c|c|c|}
\hline Variable $^{\mathrm{a}}$ & Category & Adjusted odds ratio $^{b}$ & 95\% confidence interval & $P$ value \\
\hline \multirow{2}{*}{ Milking cattle } & Yes & 1.88 & \multirow{2}{*}{$1.21-2.94$} & \multirow{2}{*}{0.005} \\
\hline & No & Reference & & \\
\hline \multirow{2}{*}{ General healthcare of cattle } & Yes & 2.40 & \multirow{2}{*}{$1.46-3.93$} & \multirow{2}{*}{$<0.001$} \\
\hline & No & Reference & & \\
\hline \multirow{2}{*}{ Birth assistance } & Yes & 2.07 & \multirow{2}{*}{$1.31-3.27$} & \multirow{2}{*}{0.002} \\
\hline & No & Reference & & \\
\hline \multirow{2}{*}{ Contact raw milk } & Yes & 2.47 & \multirow{2}{*}{$1.50-4.06$} & \multirow{2}{*}{$<0.001$} \\
\hline & No & Reference & & \\
\hline \multirow{2}{*}{ Contact cattle manure } & Yes & 3.23 & \multirow{2}{*}{$1.92-5.44$} & \multirow{2}{*}{$<0.001$} \\
\hline & No & Reference & & \\
\hline \multirow{2}{*}{ Contact dead-born animals } & Yes & 3.45 & \multirow{2}{*}{$2.16-5.50$} & \multirow{2}{*}{$<0.001$} \\
\hline & No & Reference & & \\
\hline
\end{tabular}

${ }^{\text {a }}$ The variables included were those with a $P \leq 0.20$ obtained in the bivariate analysis.

${ }^{\mathrm{b}}$ Adjusted by age and the rest of characteristics included in this table.

TABLE 5: Multivariate logistic regression analysis of farm-based characteristics associated with Coxiella burnetii positivity among cattle farmers and farm residents in three northeastern provinces and Inner Mongolia Autonomous Region, China.

\begin{tabular}{|c|c|c|c|c|}
\hline Variable $^{\mathrm{a}}$ & Category & Adjusted odds ratio $^{\mathrm{b}}$ & 95\% confidence interval & $P$ value \\
\hline \multirow{2}{*}{ Urbanization } & Rural area & 3.66 & \multirow{2}{*}{$2.25-5.96$} & \multirow{2}{*}{$<0.001$} \\
\hline & Moderate or minor urban area & Reference & & \\
\hline \multirow{2}{*}{ Laying hens on farm } & Yes & 2.04 & \multirow{2}{*}{$1.25-3.32$} & \multirow{2}{*}{0.004} \\
\hline & No & Reference & & \\
\hline \multirow{2}{*}{ Use of silage } & Yes & 1.99 & \multirow{2}{*}{$1.15-3.44$} & \multirow{2}{*}{0.013} \\
\hline & No & Reference & & \\
\hline \multirow{2}{*}{ Presence of mice and/or rats in the stable } & Present & 2.49 & \multirow{2}{*}{$1.58-3.91$} & \multirow{2}{*}{$<0.001$} \\
\hline & Absent & Reference & & \\
\hline \multirow{2}{*}{ Presence of disinfection equipment } & Yes & 0.58 & \multirow{2}{*}{$0.37-0.90$} & \multirow{2}{*}{0.015} \\
\hline & No & Reference & & \\
\hline
\end{tabular}

${ }^{a}$ The variables included were those with a $P \leq 0.20$ obtained in the bivariate analysis.

${ }^{\mathrm{b}}$ Adjusted by age and the rest of characteristics included in this table.

In the final combined multilevel model, significant risk factors were milking cattle, general healthcare of cattle, birth assistance, contact dead-born animals, urbanization, and presence of mice and/or rats in the stable. Moreover, presence of disinfection equipment was a significant protective factor (Table 6).

\section{Discussion}

This is the first study exploring the seroprevalence in cattle farmers and farm residents in China, and one of few risk factor studies on human C. burnetii infections in farm populations worldwide [18-20], suggesting that living and or working on cattle farm has a high lifetime risk for acquiring $C$. burnetii infection. Farmers and other household members are usually at highest risk for acquiring C. burnetii infection due to close contact with infected cattle and contaminated stables on farms.

The detected seroprevalence was high not only for the farmers (38.3\%), as expected, but also among spouses (31.5\%), children (31.1\%), and others (37.1\%) who lived and often also worked at the farm. The present seroprevalence obviously overs the estimates of $10.2 \%$ in the people studied to date in China [14]. The seroprevalence was also lower than those in other studies focusing on, nonfurther specified, farm populations, such as $49 \%$ among farmers from Northern Ireland [21], 72.1\% in dairy cattle farmers in the Netherlands [18], but was comparable to the $27 \%$ seroprevalence in a farm cohort in the United Kingdom [10]. However, it is complicated to compare these seroprevalences due to some differences, including geographical conditions, the different study populations, diagnostic methods, and living styles. Moreover, in the present study, females have a higher seroprevalence than males. It is contrary to other places in the world where studies have suggested that males are more susceptible to $C$. burnetii infection [2]. Routine activities of women in rural areas including taking care of livestock and cleaning stables result in the high prevalence in females in China [14].

Several independent individual and farm-based risk factors for C. burnetii seropositivity were found such as working 
TABLE 6: Combined multilevel analysis of participant- and farm-based characteristics associated with Coxiella burnetii seropositivity among cattle farmers and farm residents in three northeastern provinces and Inner Mongolia Autonomous Region, China.

\begin{tabular}{|c|c|c|c|c|}
\hline Variable $^{\mathrm{a}}$ & Category & Adjusted odds ratio $^{\mathrm{b}}$ & 95\% confidence interval & $P$ value \\
\hline \multirow{2}{*}{ Milking cattle } & Yes & 2.09 & \multirow{2}{*}{$1.33-3.27$} & \multirow{2}{*}{0.001} \\
\hline & No & Reference & & \\
\hline \multirow{2}{*}{ General healthcare of cattle } & Yes & 2.25 & \multirow{2}{*}{$1.38-3.67$} & \multirow{2}{*}{0.001} \\
\hline & No & Reference & & \\
\hline \multirow{2}{*}{ Birth assistance } & Yes & 1.86 & \multirow{2}{*}{$1.18-2.92$} & \multirow{2}{*}{0.005} \\
\hline & No & Reference & & \\
\hline \multirow{2}{*}{ Contact dead-born animals } & Yes & 2.67 & \multirow{2}{*}{$1.69-4.45$} & \multirow{2}{*}{$<0.001$} \\
\hline & No & Reference & & \\
\hline \multirow{2}{*}{ Urbanization } & Rural area & 2.34 & \multirow{2}{*}{$1.41-3.45$} & \multirow{2}{*}{$<0.001$} \\
\hline & Moderate or minor urban area & Reference & & \\
\hline \multirow{2}{*}{ Presence of mice and/or rats in the stable } & Present & 1.95 & \multirow{2}{*}{$1.38-3.01$} & \multirow{2}{*}{0.002} \\
\hline & Absent & Reference & & \\
\hline \multirow{2}{*}{ Presence of disinfection equipment } & Yes & 0.37 & \multirow{2}{*}{$0.20-0.49$} & \multirow{2}{*}{$<0.001$} \\
\hline & No & Reference & & \\
\hline
\end{tabular}

${ }^{\mathrm{a}}$ The variables included were those with a $P \leq 0.20$ obtained in the bivariate analysis.

${ }^{\mathrm{b}}$ Adjusted by age and the rest of characteristics included in this table.

and/or living in farm, milking cattle, general healthcare of cattle, birth assistance, contacting raw milk, contacting cattle manure, contacting dead-born animals, urbanization, laying hens on farm, use of silage, presence of mice and/or rats in the stable, presence of disinfection equipment, and birds in stable. The individual risk factor involving direct contact with cattle or dust-producing activities in the cattle stable, such as milking, general healthcare of cattle, clean stables, birth assistance, contacting raw milk, contacting cattle manure, and contacting dead-born animals, reflects the stable environment contact [22]. Under these circumstances the risk of inhalation of contaminated aerosols is high, with a potential increased risk for acquiring an infection. The degree of total farm animal contact has been reported to seem more important than particular animal exposure, suggesting that risk of C. burnetii exposure is largely connected with farm environment contact $[6,22]$.

Two farm-related risk factors were identified to be associated with human seropositivity among cattle farm residents/ staff: urbanization and presence of mice and/or rats in the stable. The concentration and management of cattle farming in the rural area of the study regions possibly promoted transmission between farms. The presence of mice and/or rats in the stable was observed as risk factor for human seropositivity, suggesting C. burnetii introduction or facilitation of spread by infected wild animals [23-25]. Moreover, presence of disinfection equipment was observed as protective factor for human seropositivity.

It is worth noting that $\mathrm{Q}$ fever is out of notifiable diseases in China and thus it is not easy to get test facilities. Most cases are diagnosed through retrospective and epidemiological studies which implies that misdiagnosis often occurred for acute cases, resulting in the greater possibility of chronic infections which have a poor prognosis and high mortality [14]. Thus, routine serological follow-up is helpful for prevention as well as basic biological safety rules, such as hygiene measures and the use of protection clothes.

To conclude, high C. burnetii seroprevalences demonstrate that cattle farmers and farm residents have a substantial lifetime risk for acquiring this zoonotic infection. We recommend reinforcing routine biosecurity measures to avoid indirect spread, avoiding access of companion and wild animals to the stable, and offer advice on eliminating nuisance animals in the cattle stables. Clinicians should strengthen their awareness to consider $\mathrm{Q}$ fever in this occupational group presenting with compatible symptoms or relevant sequelae to allow diagnosis and therapy in time.

\section{Conflict of Interests}

The authors declare that there is no conflict of interests in this paper.

\section{Acknowledgment}

Project support was provided by the project National Natural Science Foundation of China (Grant no. 31272566).

\section{References}

[1] E. Rousset, M. Berri, B. Durand et al., "Coxiella burnetii shedding routes and antibody response after outbreaks of $\mathrm{Q}$ fever-induced abortion in dairy goat herds," Applied and Environmental Microbiology, vol. 75, no. 2, pp. 428-433, 2009.

[2] M. Maurin and D. Raoult, "Q fever," Clinical Microbiology Reviews, vol. 12, no. 4, pp. 518-553, 1999.

[3] A. Rodolakis, "Q fever in dairy animals," Annals of the New York Academy of Sciences, vol. 1166, pp. 90-93, 2009.

[4] H. Tissot-Dupont, M.-A. Amadei, M. Nezri, and D. Raoult, "Wind in November, Q fever in December," Emerging Infectious Diseases, vol. 10, no. 7, pp. 1264-1269, 2004. 
[5] W. van der Hoek, P. M. Schneeberger, T. Oomen et al., "Shifting priorities in the aftermath of a Q fever epidemic in 2007 to 2009 in The Netherlands: from acute to chronic infection," Euro Surveillance, vol. 17, no. 3, p. 20059, 2012.

[6] D. R. Thomas, L. Treweek, R. L. Salmon et al., "The risk of acquiring Q fever on farms: a seroepidemiological study," Occupational and Environmental Medicine, vol. 52, no. 10, pp. 644647, 1995.

[7] E. Angelakis, O. Mediannikov, C. Socolovschi et al., "Coxiella burnetii-positive PCR in febrile patients in rural and urban Africa," International Journal of Infectious Diseases, vol. 28, pp. 107-110, 2014.

[8] C. A. Errasti, M. M. Baranda, J. L. H. Almaraz et al., "An outbreak of Q fever in the Basque country," Canadian Medical Association Journal, vol. 131, no. 1, pp. 48-49, 1984.

[9] G. Dupuis, J. Petit, O. Péter, and M. Vouilloz, "An important outbreak of human Q fever in a Swiss alpine valley," International Journal of Epidemiology, vol. 16, no. 2, pp. 282-287, 1987.

[10] D. Guigno, B. Coupland, E. G. Smith, I. D. Farrell, U. Desselberger, and E. O. Caul, "Primary humoral antibody response to Coxiella burnetii, the causative agent of Q fever," Journal of Clinical Microbiology, vol. 30, no. 8, pp. 1958-1967, 1992.

[11] T. Schneider, H. U. Jahn, D. Steinhoff et al., "A Q fever epidemic in Berlin. The epidemiological and clinical aspects," Deutsche Medizinische Wochenschrift, vol. 118, no. 19, pp. 689-695, 1993.

[12] B. Schimmer, F. Dijkstra, P. Vellema et al., "Sustained intensive transmission of Q fever in the south of the Netherlands, 2009," Eurosurveillance, vol. 14, no. 19, Article ID 19210, 2009.

[13] T. J. Marrie, D. Langille, V. Papukna, and L. Yates, “Truckin' pneumonia-an outbreak of Q fever in a truck repair plant probably due to aerosols from clothing contaminated by contact with newborn kittens," Epidemiology and Infection, vol. 102, no. 1, pp. 119-127, 1989.

[14] H. S. El-Mahallawy, G. Lu, P. Kelly et al., "Q fever in China: a systematic review, 1989-2013," Epidemiology and Infection, vol. 143, no. 4, pp. 673-681, 2015.

[15] W. Cong, Q.-F. Meng, X.-F. Shan et al., "Coxiella burnetii (Q fever) infection in farmed ruminants in three northeastern provinces and inner Mongolia autonomous region, China," Vector-Borne and Zoonotic Diseases, vol. 15, no. 8, pp. 512-514, 2015.

[16] M. C. A. Wegdam-Blans, C. C. H. Wielders, J. Meekelenkamp et al., "Evaluation of commonly used serological tests for detection of Coxiella burnetii antibodies in well-defined acute and followup sera," Clinical and Vaccine Immunology, vol. 19, no. 7, pp. 1110-1115, 2012.

[17] M. C. A. Wegdam-Blans, L. M. Kampschreur, C. E. Delsing et al., "Chronic Q fever: review of the literature and a proposal of new diagnostic criteria," The Journal of Infection, vol. 64, no. 3, pp. 247-259, 2012.

[18] B. Schimmer, N. Schotten, E. van Engelen, J. L. A. Hautvast, P. M. Schneeberger, and Y. T. H. P. van Duijnhoven, "Coxiella burnetii seroprevalence and risk for humans on dairy cattle farms, the Netherlands, 2010-2011," Emerging Infectious Diseases, vol. 20, no. 3, pp. 417-425, 2014.

[19] B. Schimmer, A. Lenferink, P. Schneeberger et al., "Seroprevalence and risk factors for Coxiella burnetii ( $\mathrm{Q}$ fever) seropositivity in dairy goat farmers' households in the Netherlands, 20092010," PLoS ONE, vol. 7, no. 7, Article ID e42364, 2012.

[20] R. Van den Brom, B. Schimmer, P. M. Schneeberger, W. A. Swart, W. van der Hoek, and P. Vellema, "Seroepidemiological survey for Coxiella burnetii antibodies and associated risk factors in Dutch livestock veterinarians," PLoS ONE, vol. 8, no. 1, Article ID e54021, 2013.

[21] C. McCaughey, J. McKenna, C. McKenna et al., "Human seroprevalence to Coxiella burnetii (Q fever) in Northern Ireland," Zoonoses and Public Health, vol. 55, no. 4, pp. 189-194, 2008.

[22] H. Bernard, S. O. Brockmann, N. Kleinkauf et al., "High seroprevalence of Coxiella burnetii antibodies in veterinarians associated with cattle obstetrics, Bavaria, 2009," Vector-Borne and Zoonotic Diseases, vol. 12, no. 7, pp. 552-557, 2012.

[23] A. Psaroulaki, D. Chochlakis, E. Angelakis, I. Ioannou, and Y. Tselentis, "Coxiella burnetii in wildlife and ticks in an endemic area," Transactions of the Royal Society of Tropical Medicine and Hygiene, vol. 108, no. 10, pp. 625-631, 2014.

[24] G.-W. Shin, E.-J. Kim, H.-B. Lee, and H.-S. Cho, "The prevalence of Coxiella burnetii infection in wild Korean water deer, Korea," The Journal of Veterinary Medical Science, vol. 76, no. 7, pp. 1069-1071, 2014.

[25] D. González-Barrio, E. Maio, M. Vieira-Pinto, and F. Ruiz-Fons, "European rabbits as reservoir for Coxiella burnetii," Emerging Infectious Diseases, vol. 21, no. 6, pp. 1055-1058, 2015. 


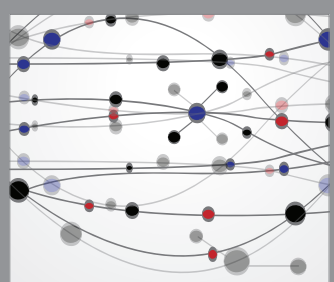

The Scientific World Journal
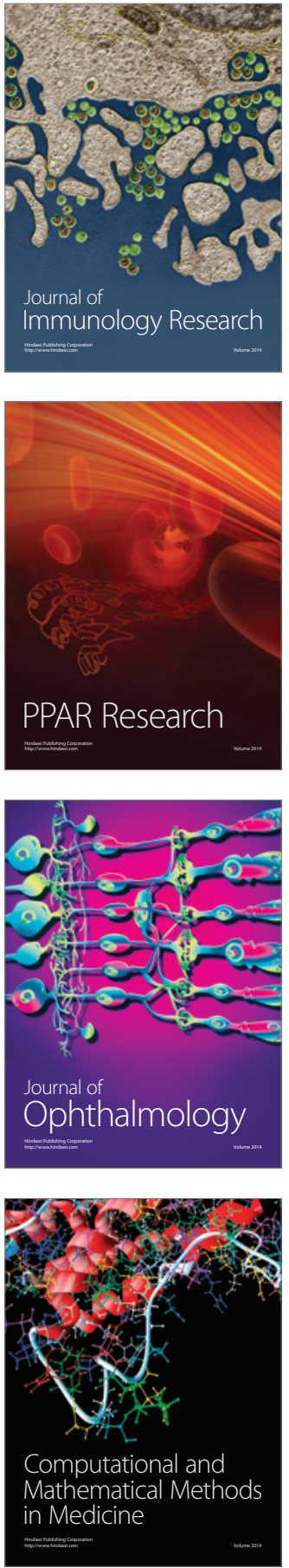

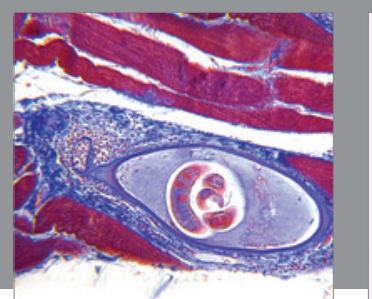

Gastroenterology Research and Practice

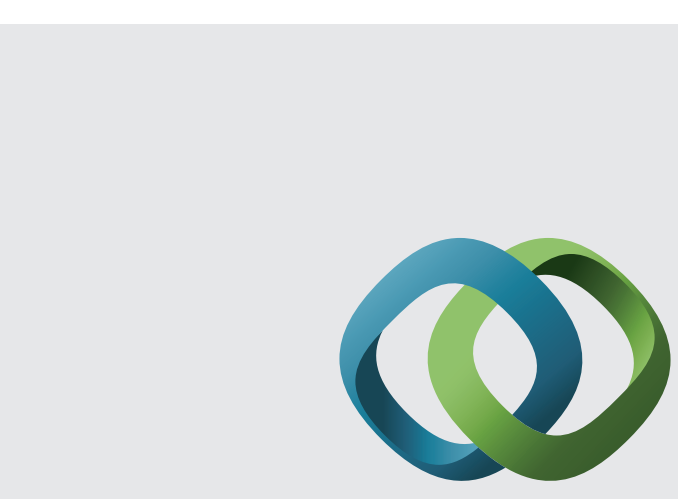

\section{Hindawi}

Submit your manuscripts at

http://www.hindawi.com
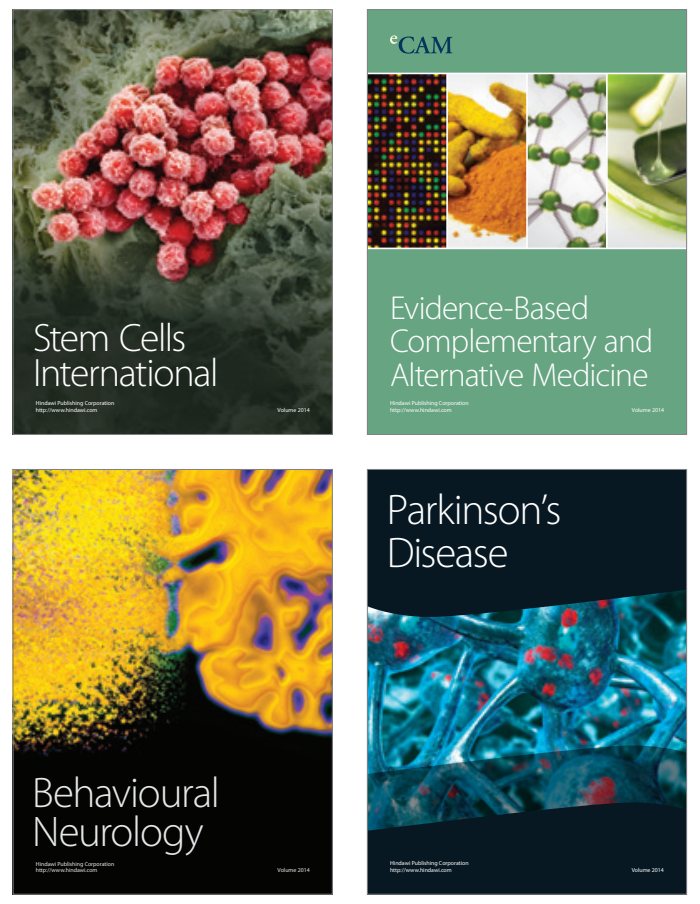
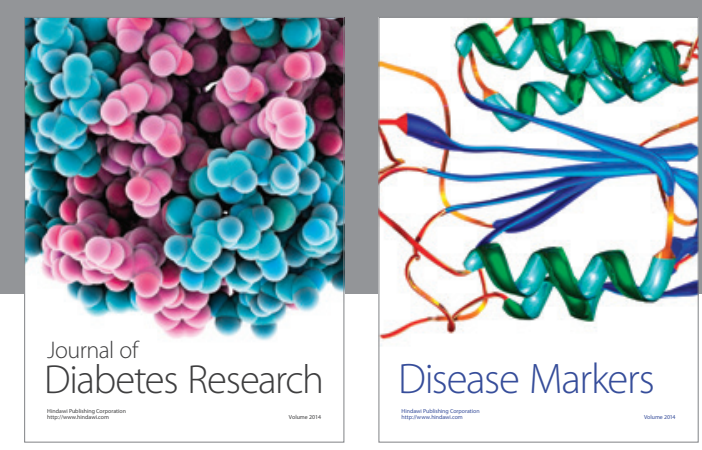

Disease Markers
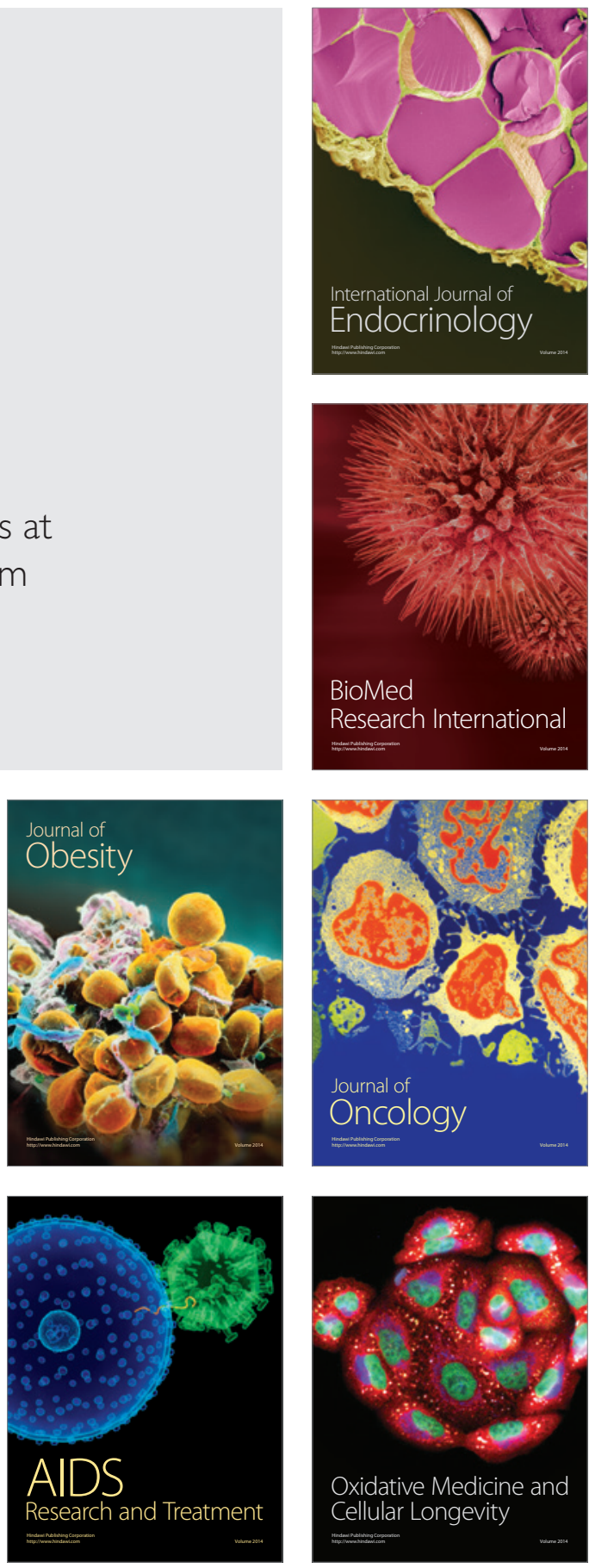